\title{
De tyske Rigsdagsvalg i Nordslesvig $1871-1912$.
}

Af Nikolaj Andersen.

Ved del sidste tyske Rigsdıgswalg den 12. Januar 1912 bier Afstemningen i Nordslesvig en opmuntrende Sejr for Landsdelens danske Befolkning: i Sammenligning med Rigsdagsvalget for fem Aar siden havde det danske Stemmetal en Tilvækst af over 1800, medens Tyskerne tilsammen kun havde en Fremgang af 555 og Socialisterne af 465 Stemmer; og dertil kommer, at Trangsfortyskningens nidkæreste Apostel, Dr. Hain, som Kandidat i forste Valgkreds fik 178 Steminer frerle end i 19017 .

Til en rigtig bedimmelse af Forholdene vil det imid!ertid rere formalstienligt ikke blot at drage en Sarmenligning mellem Stemmetallene ved de to sidste Rigstiliwialg, men tillige og navnlig at betragte Stiliz:yen paa (irundlag af de red samtlige foregaaende Rigsdagsvalg i Nordslesvig afgivne Stemmer; og da der, saa ridt vides, ikke foreligger nogen senere samlet Oversigt over de paagældende Tal end den, der findes $\mathrm{i}$ »Haandbog $\mathrm{i}$ det nordslesvigske Spørgsmaals Historie" og kun gaar til 1898 , skal der her i 
al Korthed gives en Fremstilling af Resultaterne ved samtlige tyske Rigsdagsvalg i Nordslesvig siden 1sil.

Fremstillingen vil dele sig i to naturlige Hovedafsnit, idet der forst ril blive hidsat en Række absolute Tal, nemlig Antallene af de virkelig afgirne danske, tyske og socialistiske Stemmer i mindre og storre Distrikter, og der derpara vil folge en Del relatire Tal, d. v. s. Antallene af de danske, tyske og til Dels socialistiske stemmer i Hundrededels-Forhold til summen af de patagexldende afgirne stemmer, ligeledes indeinfor enkeite og samlede Ommader.

De redfujede Diagrammer vil forhaabentlig delvis kunne bode paa sarnet af mange og lange Komme:tianer.

\section{ค. Absolute $\tau_{a I}$.}

\section{De danske Stemmer.}

\section{a. Byerne.}

1. Købst de r ne.

Forst hidsættes Antallene af de i de nordslesvigske Kobstæder Hadersler, Sunderborg, Aabenraa, Flenshorg og Tonder siden 1871 afgivne danske Stemmer. For Tonders Vedkommende mangler dog enkelte Tal.

\begin{tabular}{|c|c|c|c|c|c|}
\hline & lev & $\begin{array}{l}\text { Somder- } \\
\text { borg }\end{array}$ & $\begin{array}{l}\text { Aabent- } \\
\text { raa }\end{array}$ & $\begin{array}{l}\text { Flens- } \\
\text { borg }\end{array}$ & \\
\hline & 638 & (190 & 370 & & \\
\hline & & & & & \\
\hline & & & 3 & & \\
\hline & & & & & \\
\hline & & & 206 & & \\
\hline & & $2 \pi$ & 234 & 1020 & \\
\hline & 309 & 216 & 22.5 & 1024 & \\
\hline
\end{tabular}




\section{Tabel I.}

De danske Stemuntal i de rnkelte Kohstader og Flakker. \& हो ह हो इ के हो हो

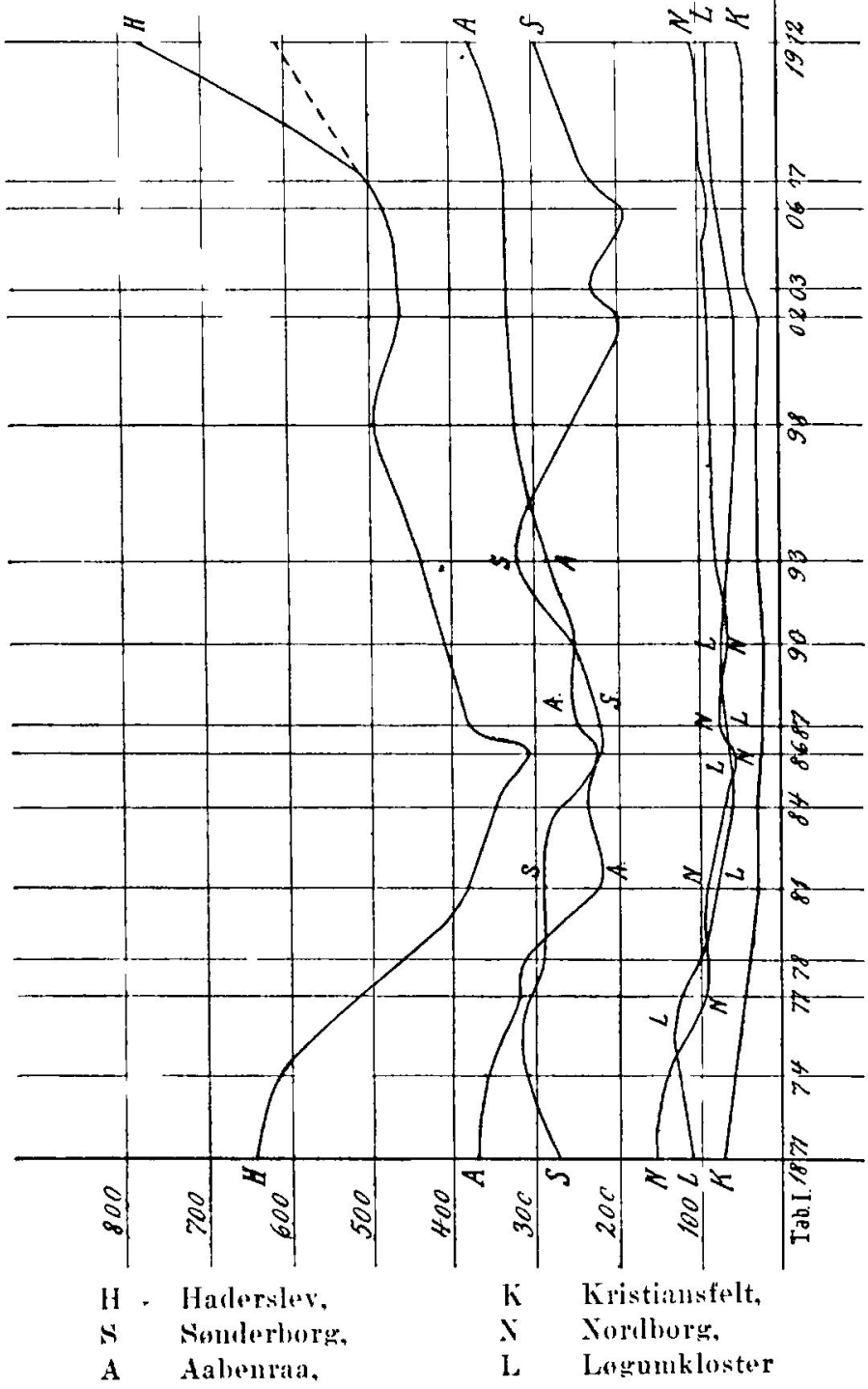




\begin{tabular}{|c|c|c|c|c|c|}
\hline Aar & $\begin{array}{l}\text { Haders- } \\
\text { lov }\end{array}$ & $\begin{array}{c}\text { Souder- } \\
\text { horer }\end{array}$ & $\begin{array}{c}\text { Aabell- } \\
\text { raa }\end{array}$ & $\begin{array}{l}\text { Flens- } \\
\text { borg }\end{array}$ & $\begin{array}{l}T+11- \\
d * r\end{array}$ \\
\hline $18 \times 7$ & 379 & 2.25 & 250 & 797 & - \\
\hline $1 \times 90$ & איא & 250 & 249 & (0) & 19 \\
\hline 1898 & 434 & 320 & $\underline{9} 9 \cdot$ & 471 & -1 \\
\hline איא & 497 & 259 & 318 & 485 & \\
\hline 190.3 & 462 & אופ & - & - & - \\
\hline 19083 & $4(65)$ & $2: 30$ & 3333 & 442 & 28 \\
\hline $190 ;$ & AK8 & 191 & - & - & 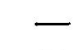 \\
\hline 1907 & (1) & 232 & 333 & 42.2 & \\
\hline 1912 & 777 & 2916 & 374 & 456 & \\
\hline
\end{tabular}

I Haderslev By er der siden 1907 blevet indlemmet et Par Forstæder, som tidligere regnedes til Ianddistrikterne; relativt er altsaa Tallet 777 i Anret 1912 for hajt, mon hvor meget, fremgatr ikke af de officielle Valgresultater. I Aaret 1907 bler der indenfor det Omrande, der nu svarer til Haderslev Kobstad, afgivet (66.) danske Stemmer. - I Flensborg By er siden 1907 to Valgdistrikter bleven indlemmede, hvor der red forrige Rigsditgswalg afgaves tilsammen 9 dinske Stemmer.

2. Flæk kerne.

Batade ublandede og fuldstændige officielle Tal haves fra Flakkerne Kristiansfelt, Nordborg, Augustenborg, Logumkloster og Hojer.

Aar Kristi- Xord- Augu- Lagumansfelt borgestemborg kloster Ilajer

$\begin{array}{rrrrrrr}1871 & 68 & 150 & 9 & 111 & - \\ 1874 & 58 & 145 & 8 & 128 & - \\ 1877 & 48 & 93 & 5 & 125 & - \\ 1878 & 40 & 92 & 8 & 103 & - \\ 1881 & 29 & 90 & 2 & 75 & - \\ 1884 & 29 & 70 & 1 & 64 & - \\ 1886 & 23 & 59 & 2 & - & -\end{array}$


Aar Kristi- Norl- Aunu- Lugumallsfelt borestenhorg kluster Hojor

$\begin{array}{rrrrrr}1887 & 23 & 75 & 4 & \text { 一 } & - \\ 1890 & 21 & 65 & 1 & 71 & 9 \\ 18993 & 30 & 79 & 7 & 65 & 6 \\ 1899 & 30 & 87 & 11 & 54 & - \\ 1909 & 27 & 90 & 19 & - & - \\ 19093 & 38 & 94 & 11 & (92 & 3 \\ 1906 & 3 !) & 89 & 31 & - & - \\ 1907 & 45 & 90 & 31 & 78 & 10 \\ 1912 & 44 & 104 & 29 & 85 & 4\end{array}$

\section{b. Landet.}

1. Haders le rosteramt.

Haderslev losteramt deles naturligst i folgende tre Omlrader:

1. Nordenfjordssognene: Gammel-Haderslev, Hammeler, Moltrup, Bjerning, Hjerndruy, Stepring, Frorup, Tyrst]u], Aller, Fjelstrup, Vonsbek og Aastrup Sogne;

2. Sondenfjordssognene: Starup, (iarup, Osby, Halk, Vilstrup, Hoptrup og Tedsted Sogne;

3. Jarnvejnsognene: Oksenvad, Sommersted, Maugstrup, Jagerup, Skrydstruy og Nustrup) Sogne.

Orer Talrakkerne betegnes Nordenfjordssognene med N. F, Sondenfjordssognone und S. F. ogr .Jernrejssognene med J. I.

\begin{tabular}{|c|c|c|c|c|}
\hline$A: r$ & N. F. & $\therefore$ F. & J. $V$ & tilsam \\
\hline 1871 & 16918 & 1132 & 815 & 3640 \\
\hline 1874 & 1542 & 9()() & $7 \geq 6$ & אד.2.3 \\
\hline 1877 & 1412 & 911 & $(33.5)$ & אז.90ב \\
\hline 1878. & 1319 & 846 & (i) & 2798 \\
\hline $18 \times 1$ & $1201 / 4$ & $7 \cdot 01$ & 57.5 & $25(1)$ \\
\hline $18 \times 1$ & 1127 & $7(0)$ & 520 & 23.52 \\
\hline
\end{tabular}




\begin{tabular}{|c|c|c|c|c|}
\hline Lar & S. F. & S. F. & \multicolumn{2}{|c|}{ J. V.tilsamment } \\
\hline 1 ision & 1078 & 652 & האי & 2.248 \\
\hline 18রT & $10 \times 3$ & 748 & 534 & $23(35)$ \\
\hline 1800 & $113: 3$ & 737 & 559 & 2 -1:29) \\
\hline $189: 3$ & $12 \cdot 9)$ & 772 & (j4.) & $2(i) 40$ \\
\hline 1898 & $1 \geq(j !)$ & 819 & (i9) 1 & 2779 \\
\hline $19(1)=2$ & 1330 & 8016 & 700 & $28 ; 36$ \\
\hline $190 \%$ & 1351 & $8: 33$ & $7(06$ & 2910 \\
\hline $1906 i$ & 1332 & $8: 35$ & $71 !$ & 2886 \\
\hline 19() 7 & $1: 37: 2$ & 859 & 717 & 只!仿 \\
\hline $191=$ & $1: 3$ 午 & 1013 & $7 ! !)$ & 3158 \\
\hline
\end{tabular}

2. Ha rerslev Vesteramt.

Hadersler Vestermut kan ligeledes deles i tre I)ele, nemlig:

1. Roddlingegnen med Sognene: Rodding, Hygum, Lintrup, Hjerting, Sikrare, Skolborg. Jels, Oster- Lindet, (iman on Fol;

2. Toftlundegnen med siognene: Toftlund, Tirslund, Bestoft, Agrerskor og Bramderuul;

3. Hviluling Herred med Sognene: Hvidding, Roager, Folder, Spandet, Ilojiul, Arrild, Skarbak, Brons og Rejsby.

(Mer Tialrakkerne botogness Roxldingegnen med R. E., Toftumdegmen med T. E. og Hvidding Herred meil H. H.

\begin{tabular}{|c|c|c|c|c|}
\hline Ain & IR. E. & T. E. & H. H. & tils. \\
\hline 1871 & 17.59 & 841 & 1093 & $366)$ \\
\hline 1574 & 1.504 & 77.5 & (9) & $3: 3(1)$ \\
\hline $1 \times 7$ & $1: 39: 2$ & 7115 & $N(i ;)$ & 2971 \\
\hline IBTE & $1: 3: 20$ & 711 & 774 & 2805 \\
\hline $1 \times \times 1$ & 1194 & (j)1 & 7 促 & 2.577 \\
\hline 18x' & $10 \div 2$ & )999 & 677 & 2300 \\
\hline $18 \operatorname{lig}$ & 976 & 597 & 61:3 & $2-216$ \\
\hline
\end{tabular}




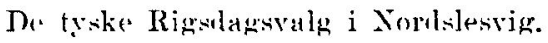

\begin{tabular}{|c|c|c|c|c|}
\hline Aar & R. E. & 'I. E. & H. H. & tils. \\
\hline $18 \times 7$ & $10(69)$ & (i330) & 6900 & 2389 \\
\hline $18(x)$ & 10.59 & $6(3.5)$ & 711 & 2435 \\
\hline 1893 & 1147 & 793 & 764 & 2704 \\
\hline 1896 & 12.52 & 817 & 852 & $29-1$ \\
\hline 1902 & 1275 & 779 & 仿 & $2 \times 99$ \\
\hline $19(1) 3$ & 1316 & 797 & 9()$, y$ & 3022 \\
\hline $190(3$ & 1417 & $8: 34$ & $8 \times 7$ & $31: 38$ \\
\hline 1907 & 1\}1! & 817 & 876 & 3112 \\
\hline 1912 & 1633 & 9) 14 & 981 & $35-8$ \\
\hline
\end{tabular}

3. sing derborg Amt.

Sonderborg Ant deler sig af sig selv $i$ forlgende tre Distrikter:

1. Als Norrehered med Sognene: Nordborg. Landsogn, Oksbol, Mavnbjarg, Srenst lup og Egen;

2. Als Somblerherral med sognene: Ketting, Notmark, Adserballe, Tandslet. Iysabild, Kajnes, Horup og [Thebs];

3. Sundeved med Sogneme: [Tleru], Sottrup, J)ỵbbol, Nybol og 13roager.

Betegnelsen ar her Als Norreherred: A. N., Als Gonderherred: A. S. og sundeved: Sr.

\begin{tabular}{|c|c|c|c|c|}
\hline far & 1. $\mathrm{x}$. & A. S. & ה. & tils. \\
\hline $1 \times 71$ & 10.40 & נזו & 1271 & 4129 \\
\hline $1 \times 74$ & $10.5=2$ & 18:3! & $134(1)$ & $4-2-21$ \\
\hline 1877 & ris & 107.5 & 12 保 & \\
\hline 878 & 8.1 & $1 . \overline{2}-20$ & 1106 & $34 \times 3$ \\
\hline 1 intol & $7(b i)$ & 1412 & 1083 & 321 \\
\hline 1אis' & $1 i 71$ & $13:) 1$ & $9 \times 1$ & 30103 \\
\hline & (I) & 1219 & 9) 20 & $273 x$ \\
\hline איז & (i9). & $1: 3 \geq 1$ & $10: 39$ & 3(0)5 \\
\hline (K!)() & 731 & $1: 3010$ & $106 i 6$ & $3(1) 97$ \\
\hline 6013 & $x-1$ & 13388 & 1208 & 3367 \\
\hline 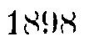 & $10(0) 1$ & 14.5.0 & 1414 & $3 \times 67$ \\
\hline
\end{tabular}




$\begin{array}{ccccc}\text { Aar } & \text { A. X. } & \text { A.s. } & \text { sv. } & \text { tils. } \\ 1902 & 911 & 1255 & 13(51 & 3527 \\ 1903 & 917 & 128 \cdot 2 & 1305 & 3504 \\ 1906 & 924 & 1250 & 1279 & 3453 \\ 1907 & 932 & 12(61 & 12(i 7 & 3455 \\ 1912 & 981 & 1450 & 1377 & 3808\end{array}$

4. A a be n r a a $A m \mathrm{t}$.

Aabenraa Ant falder naturligst i to Distrikter, nemlig:

a) Den nordvestlige Del eller Ris og Sonder-Rangstrup Herreder med Sognene: Bedsted, Hellerad, Egrad, Wstel-Logum, Loj, Ris, Hjortkar og Bjolderul);

b) Den sydostlige Del eller Lunitoft Herred med Sognene: lige, Fnsted, Felsted, Varnass, (aradatenAdsbol, Kraess, Ringenaes, Holbol (undtagen Jlunsnap By, der horer til Flensborg Ant) og Kliplex.

Betegnelsen over Talrakkerne er for den nordvestlige Del: $\mathrm{N}$. Y., og for den sydustlige Del: S. $U$.

\begin{tabular}{|c|c|c|c|}
\hline dar & ․ $r$. & S. 11. & tiln. \\
\hline 1871 & $111 i 1$ & 1321 & 2485 \\
\hline 871 & 1111 & 13.13 & 는 \\
\hline 1877 & 951 & 1203 & 2154 \\
\hline 1878 & $8 \cdot 2 \cdot 2$ & 1028 & 1850 \\
\hline 881 & 759 & $81 / 4$ & $1(i) ; 3$ \\
\hline 1884 & 841 & 10:3 & $18 ! 9 !$ \\
\hline 1886 & 830 & 1105 & 1985 \\
\hline 1887 & 932 & 1074 & $20(1) 6$ \\
\hline 1890 & 856 & 1005 & 1861 \\
\hline 1893 & 932 & 1031 & 1963 \\
\hline 1898 & 932 & 1131 & 2063 \\
\hline 1903 & 851 & 1024 & 1875 \\
\hline 1907 & 877 & 1198 & 207 \\
\hline 191 & $10(i 9)$ & 1329 & 2 \\
\hline
\end{tabular}




\section{Tabel II.}

De ranske stemmetal i de enkelte Landdistrikter.

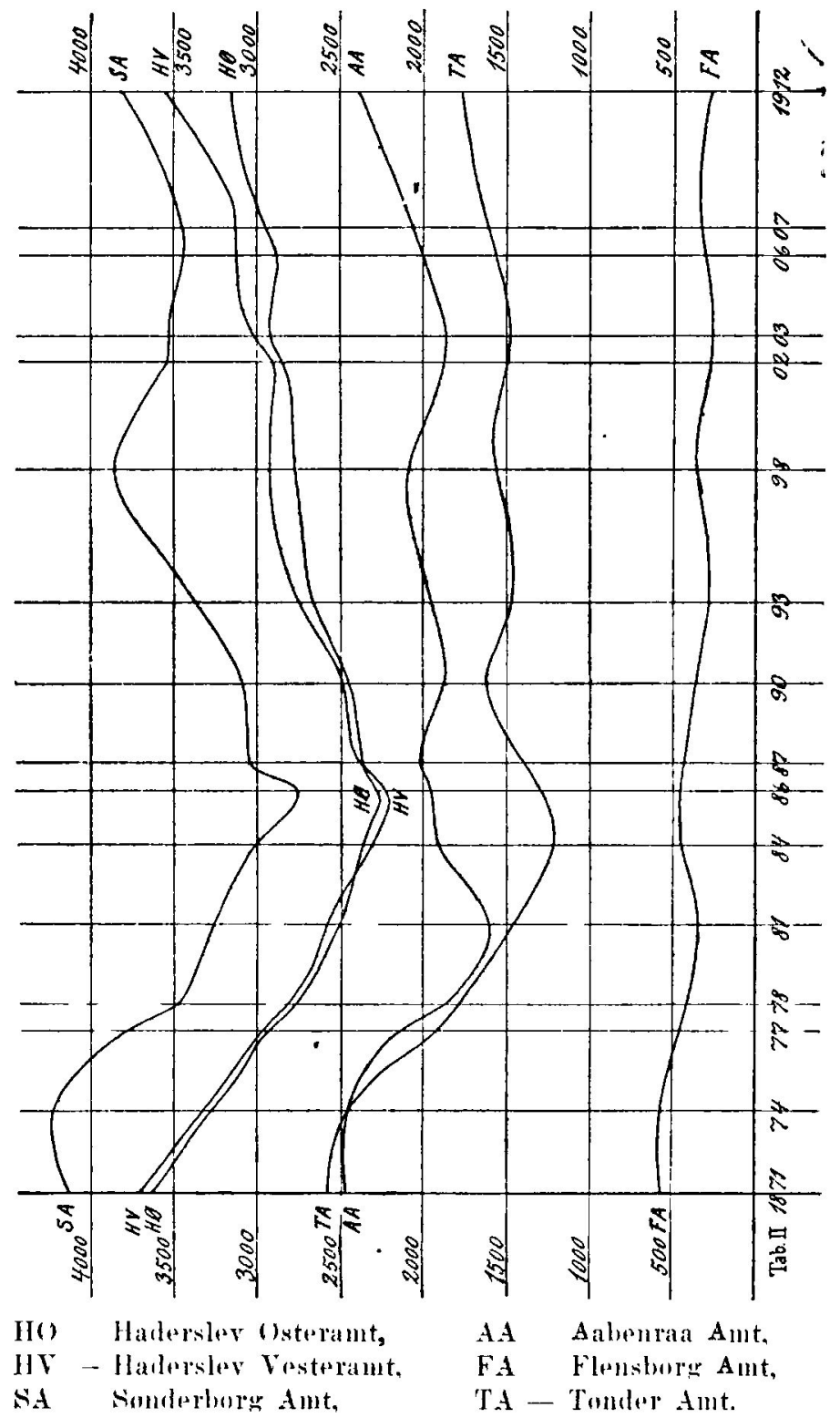




\section{Fle ns borg A m t.}

Af Flensborg Amt regnes til Nordslesvig kun Bor, Hanved og Valsbol Sogne samt Hønsnap By i Holbal Sogn. I dette Distrikt er der siden 1871 blevet afgivet folgende danske Stemmer:

$\begin{array}{cc}\text { Aar } & \text { F. A. } \\ 1 \times 71 & 575 \\ 1874 & 558 \\ 1877 & 454 \\ 1878 & 403 \\ 1881 & 351 \\ 1884 & 456 \\ 1886 & 420 \\ 1887 & 408 \\ 1890 & 364 \\ 1893 & 2860 \\ 1898 & 367 \\ 1903 & 267 \\ 1907 & 326 \\ 1912 & 282\end{array}$

i. Tonder A $\mathrm{mt}$.

Af Tonder Ant horer til Nordslesvig kun den nordlige 1)el, Tonder Norreamt, der kan deles $i$ to Distrikter, nemlig:

a) Den ostlige Del med Sognene: Norre-Logum, Lagumkloster Tandsogn. Horjst, Ravsted, Bylderup, Tingler, Burkal, Hostrul), Tonder Iandsogn og ' Abild:

b) Den restlige Del med Sognene: Romø, Ballum, Randerup, Mjollon, Mostrup, Brede, Visby, Mageltonder, Jaler, Emmerler, Hjerpsted og skast.

Betegnelien over Talrakkelne er for den ostlige Del: T. (1. or for den vestlige 1)el: T. V. 


$\begin{array}{lcrc}\text { Aar } & \text { T. (). } & \text { T. V. } & \text { tilsammen } \\ 1871 & 968 & 1616 & 2584 \\ 1874 & 910 & 1562 & 2472 \\ 1877 & 5(69 & 1339 & 1908 \\ 1878 & 500 & 1289 & 1789 \\ 1881 & 302 & 1167 & 1469 \\ 1884 & 290 & 911 & 1201 \\ 1890 & 574 & 1035 & 1609 \\ 1893 & 459 & 1020 & 1479 \\ 1898 & 398 & 1170 & 1568 \\ 19083 & 361 & 1111 & 1472 \\ 19(17 & 482 & 1125 & 1607 \\ 191.2 & 588 & 1173 & 1761\end{array}$

\section{c. By og Land.}

1. I) e nkelte Anter.

1) efterfolgende Tal gielder for de enkelte Amter i deres Melherl. altsala for By-og Landdistrikter tilsammen.

Til forste Valgkreds horer: Hadersiler Ant H. A. un simmlerborge Anut s. A.

\begin{tabular}{|c|c|c|c|}
\hline Aar & H. A. & S. 1. & tilsammer \\
\hline 1571 & $S(1)=$ & $4.5 x$ & $12(i)()$ \\
\hline ハト74 & $72: 37$ & 4lik4 & 11921 \\
\hline $1 \times 77$ & $64 \times 7$ & $4-16$ & $107(1)$ \\
\hline 1N7 & $(i 10) 7$ & $3 \times 75$ & 9982 \\
\hline 1イリ। & 可做 & $36: 23$ & 9) 107 \\
\hline 1nitat & $.71) \geq(i$ & 3:3仵 & $8: 174$ \\
\hline 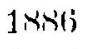 & $47)(i$ & 305.5 & 7851 \\
\hline Jixit & ; & $3: 35 !$ & N515 \\
\hline $18 !)$ & $.52 \times .5$ & 3113 & $8(i) x$ \\
\hline $1 \times 913$ & 5N14 & B7:B:3 & 9.197 \\
\hline $1 x 9 x$ & $(i \geq 2.27$ & $4 \cdot 2 \cdot 1$ & $1(14.51$ \\
\hline $1+(t) 2$ & $(i \geq 2) 1$ & $: 3 \times 31$ & 16) \\
\hline $19+1): 3$ & (j仿京 & $3 \times 39$ & 10)271 \\
\hline
\end{tabular}




$\begin{array}{lllc}\text { Aar } & \text { H. A. } & \text { s. A. } & \text { tils. } \\ 19066 & 6551 & 36(64 & 1021.5 \\ 1907 & 606 \% & 3808 & 10414 \\ 1912 & 7507 & 4237 & 11744\end{array}$

Aabenrat og Flemsborg Amter horer til anden og Tonder Amt til fjerde Valgkreds. Da det kun chrejer sig om selve Nordslesvig, er Byerne Flenshorg, Tonder og Hojer udeladte af den efterfolgende sammenstilling, hror der over Talrækkerne benyttes folgonde Afkortelser:

Aabenraa Amt: A. A., Flensborg Amt: F. A. og Tomder Amt: T. A.

\begin{tabular}{|c|c|c|c|}
\hline Aar & A. A. & F. I. & 'Т. .1. \\
\hline 1871 & 2855 & 575 & $269 \overline{1}$ \\
\hline 1874 & 2818 & 558 & 260() \\
\hline 1877 & 2465 & 4.51 & $2(13: 3$ \\
\hline 1878 & 2170 & 4013 & 1892 \\
\hline $1 \times 81$ & $18 \cdot 9$ & 3.51 & 1544 \\
\hline 188.4 & ㄹ133 & 4.56 & $12(i j)$ \\
\hline $18 \times 6 ;$ & 2160 & $4: 30$ & - \\
\hline 1KXT & 20.56 & AlN & - \\
\hline 18910 & 2110 & $36 t^{4}$ & $16 \times 0$ \\
\hline 1893 & 255 & 286 & 15.1-4 \\
\hline 1898 & 2381 & 3167 & $16: 0.2$ \\
\hline $19(1) 3$ & 20 & 2017 & 1534 \\
\hline 19() 7 & 2408 & 326 & 16 (6.j \\
\hline $1 ! 12$ & 2772 & $28: 2$ & 18.16 \\
\hline
\end{tabular}

Til Slutning hidsættes Antallene af de clanske Stemmer

a) i de nordslesvigske Kobstaxder og Flickler (ITadersler, Sonderborg og Aabenral samt Kristiansfelt, Nordborg, Augustenborg og Logumkloster) tilsammen, 
b) i alle nordslesvigske Landdistrikter (med (iraasten) tilsammen og

c) i begge Dele tilsammen, altsala i hele Nordslesvig. Dertil maa dog bemærkes, at Tallene for Tonder Nurreamt (Logumkloster og Landdistrikterne) 1886 og 1887 ikke eksisterer i Virkelighed, men blot er kalkulerede*).

\begin{tabular}{|c|c|c|c|}
\hline $\mathrm{ar}$ & Byerue & $\begin{array}{l}\text { Landidi- } \\
\text { strikterme. }\end{array}$ & $\begin{array}{l}\text { Hele Noril- } \\
\text { slesvig }\end{array}$ \\
\hline 1871 & 1616 & 17109 & 18725 \\
\hline 1874 & 1625 & 16272 & 17897 \\
\hline 1877 & 1400 & 14175 & 15575 \\
\hline 1878 & 1324 & 13123 & 14447 \\
\hline 1881 & 1090 & 11741 & 12831 \\
\hline $1 \times y_{1}$ & 10)17 & 11211 & 1.2929 \\
\hline $1 \times \times 6$ & $8 ! 99$ & 10717 & 11616 \\
\hline $1 \times 87$ & 1) 23 & 114.57 & 12480 \\
\hline $18: 90$ & 106.5 & 11795 & 12860 \\
\hline 1893 & 1227 & 12445 & 13672 \\
\hline 1898 & 12.56 & 133365 & 14821 \\
\hline $190: 3$ & 1233 & $129) \times 8$ & 14221 \\
\hline 1907 & 1310 & 13445 & 14755 \\
\hline 1912 & 1709 & 14850 & 16559 \\
\hline
\end{tabular}

Naar man betragter de hidtil anførte Tal, og narnlig naar man kaster et Blik paa de tilsvarende Diagrammer (Tab. I, II og III), vil det straks være iojnefaldende, hvad der baade $i$ det hele og i de enkelte Distrikter er karakteristisk for Berægelsen i de danske Stemmetal. Vi har forst i en Aarrække en stadig nedadgaaende Berægelse, der er en naturlig Folge af den ved Haabet om en snarlig Opfyldelse af Pragfredens $§ 5$ foraarsagede vedvarende Udvandring. Mini-

*) Efter Haandhog i det mordslesvigske Sporgsmaals Historie. 


\section{Tabel III.}

Ilanske og tyskes sibemmetal.

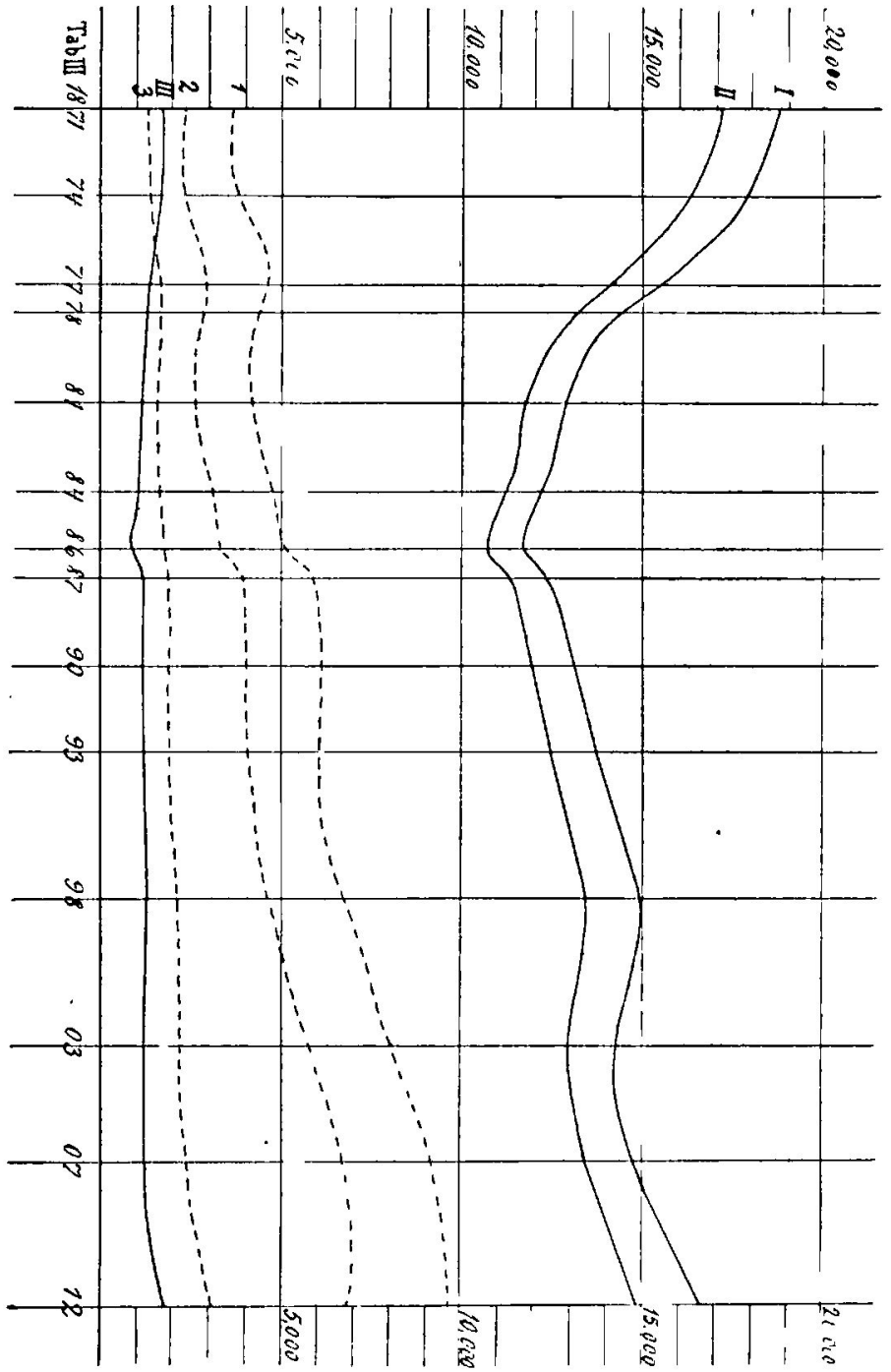

I. Danske st. i hele Nordsl. 1. Tyske st. i hele Nordsl.

II. Danske St. i samtl. Landd. 2. Tyske St. i sumtl. Landdistr. III. Danske Nt. i samtl. Byer. 3. Tyske Nt. i samtl. Byer. 
mum naas i Aaret 1886; allerede Aaret efter kan der kendes en vasentlig Stigning. Efter at nemlig Irojicen og Osterrig red Traktat af 11 . Oktober $18-8$ har elklæeret, at Pragfredens femte Artikel er wat ud af Kraft", har Idvandringen i syttenaars-Alderen begyndt at standse, og dette sjores allerede i Aaret 1887 , da det første storre Antal hjemmeblerne Syttenaarige er naliet frem til Stemmeretsalderen. Fra nu af er Bevagelsen i Almindelighed jarnt opadgaande undtagen ved de forste Valg $i$ det nye Aarhundrede, da det berygtede Optantlaveri faar det danske Stemmetal til at synke en Del paa de fleste Steder; men ofter at dette kunstige Tryk er blevet havet, er der endelig atter indtraadt en naturlig Stigning.

Ved det sidste Rigsdagsvalg er det danske Stemmetal i

hele Nordslesvig naaet op over Tallet i . 1877 de nordslesvigske Landdistrikter nataet op

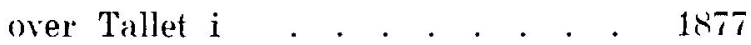

de nordslesvigske Byer nazet op over Tallet $i$ $1 \times 71$

Drager vi ogsan for de enkelte Byers og større Landdistrikter's Vedkommende en Sammenligning mellem Resultaterne ved sidste Rigsdagsvalg og ved Valgene for $18 \&(;$, ril vi finde, at det danske Stemmetal i 1912:

\section{1. i Ianddistrikterne:}

Flensborg Amt er lavere end i 1886

Tonder Norreamt naar op over Tallet i 1881 Sønderborg Amt » " " 1878 Hadersler Østeramt » $» \quad$ » 1877 
Aabenraa Amt " . \$ 1877

HaderslevVesterant : , : 1874

2. i Brerne:

Logumkloster natar op orer Tallet i 1881 Kiristiansfelt 1878

Sunclerborg

Nordborg

Haderslev

Augustenborg

Aabenraa

\section{De tyske Stemmer.}

\section{a. Byerne.}

1. Kobstaderne.

Aar Inalers- Son- Aahen- Flens- Tonder lev derbore raa horg

$\begin{array}{lllll}1871 & 452 & 212 & 408 & 1592\end{array}$

$\begin{array}{lllll}1874 & 591 & 214 & 419 & 1406\end{array}$

$\begin{array}{llllll}1877 & 64.3 & 283 & 457 & 1594 & -\end{array}$

$\begin{array}{llllll}1878 & 634 & 302 & 427 & 1841 & -\end{array}$

$1881 \quad 659 \quad 3(0) \quad 330) \quad 1602 \quad-$

$1884 \quad 668 \quad 290 \quad 423 \quad 1632 \quad-$

$1 \times 86$ 722 $309 \quad 432 \quad 1883 \quad-$

$\begin{array}{lllll}1887 & 783 & 342 & 498 & 2081\end{array}$

$1890 \quad 730 \quad 295 \quad 562 \quad 2449 \quad 481$

$\begin{array}{llllll}1893 & 683 & 300 & 548 & 2629 & 387\end{array}$

$\begin{array}{llllll}1898 & 685 & 343 & 629 & 3341 & -\end{array}$

$1902 \quad 811 \quad 434 \quad-\quad-6 \quad-$

$\begin{array}{llllll}1903 & 772 & 440 & 603 & 3396 & 439\end{array}$

$\begin{array}{llllll}1906 & 751 & 557 & - & -\end{array}$

$\begin{array}{llllll}1907 & 823 & 522 & 655 & 4871 & 569\end{array}$

$\begin{array}{llllll}1912 & 1141 & 665 & 782 & 5421 & 687\end{array}$

For Haderslers Vedkommende gælder i 1912 tilsvarende, hvad der er sagt om de danske Stemmer. 
Do tyske Rigsolagsvalg i Nordslesvig.

\section{'Tabel IV.}

De tyske Stemmetal i de eukelte Kubstader og flakker.

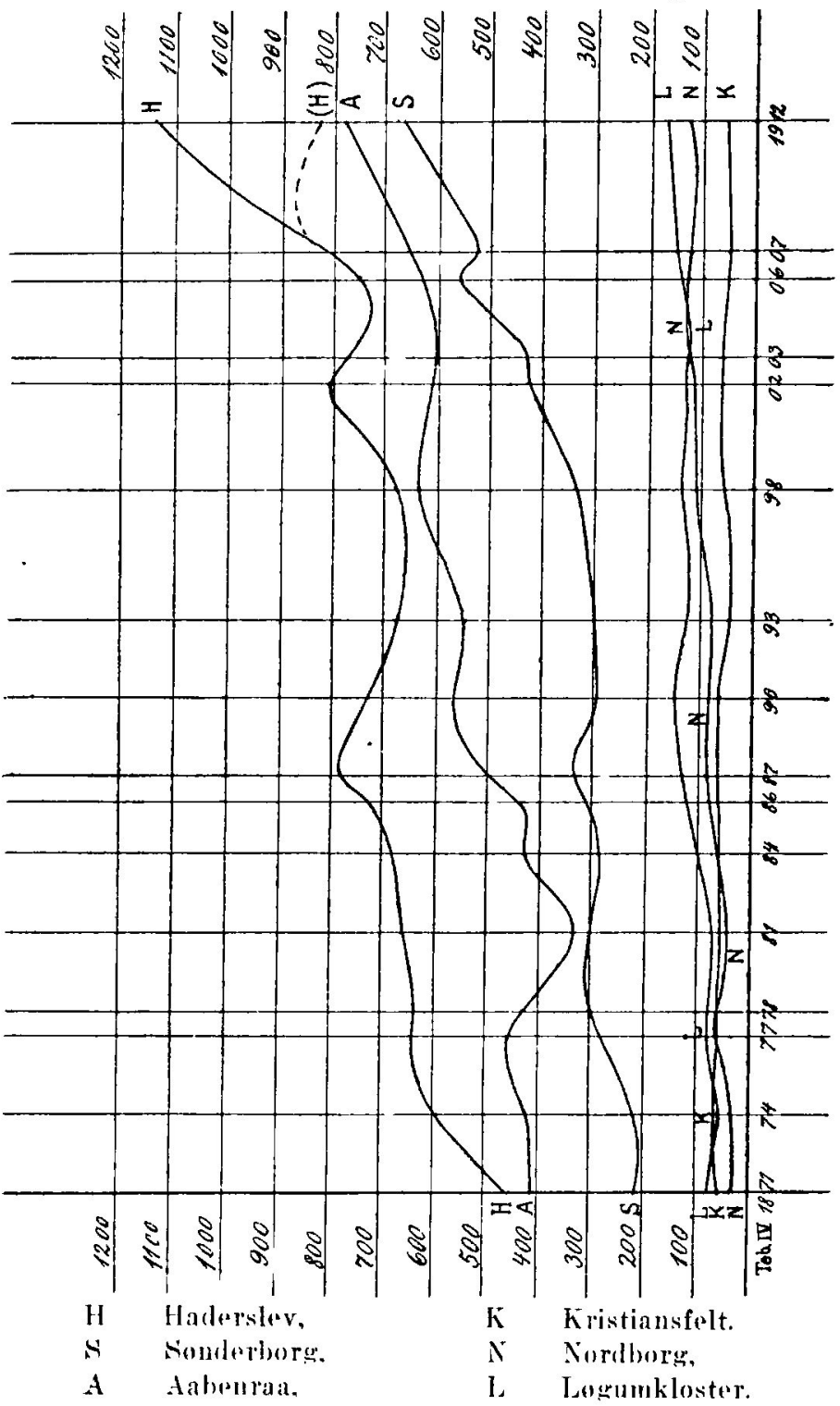


Paa Grund af Indlemmelsen af et Par Forstatlersiden $19(07$ er Tallet 1141 relativt for stort. I Aaret 1907 blev der indenfor det Omrade, der nu svarer til Haderslev Kobstad, afgivet 1141) Stemmer.

2. F la k k r ne.

Aar Kristi- Sorr- Aura- Logumansfelt borg stenborg kloster Hojer

\begin{tabular}{|c|c|c|c|c|c|}
\hline 1871 & .33 & 84 & 50 & 69 & - \\
\hline 1874 & 60 & 35 & 45 & 57 & - \\
\hline 277 & 57 & 5 & 87 & 76 & $\ldots$ \\
\hline 78 & 55 & 53 & 84 & (6.5) & - \\
\hline 81 & 53 & 49 & 83 & 70 & 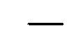 \\
\hline 184 & .54 & (i) & 83 & (9) & - \\
\hline $8(i$ & 53 & 77 & 86 & - & - \\
\hline 187 & 53 & א & 102 & - & - \\
\hline() & 54 & 77 & $x(1)$ & 149 & $10 / 4$ \\
\hline 3913 & 47 & 70 & 177 & 119 & 124 \\
\hline 398 & 52 & או1 & 74 & 138 & 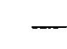 \\
\hline (1) 2 & 57 & 116 & $\mathrm{~B} !)$ & - & - \\
\hline 80 & 56 & 124 & 101 & 123 & $15 \pi$ \\
\hline$x$ & 51 & $128^{\circ}$ & $8 \cdot 2$ & - & - \\
\hline 07 & 52 & 120 & 94 & 1.55 & 1.5 \\
\hline 11 & 52 & $1: 27$ & גה & 169 & 2010 \\
\hline
\end{tabular}

b. Landet.

1. Hadersley osteramt.

Nordenfjordssognene betegnes med N. F., Sondenfjordssognene med $\mathrm{S}$. F. og Jærnvejssognene med J. V.

$\begin{array}{rrrrc}\text { Aar } & \text { N. F. } & \text { S. F. } & \text { J. V. } & \text { tilsammen } \\ 1871 & 144 & 193 & 86 & 423 \\ 1874 & 150 & 225 & 133 & 508 \\ 1877 & 160 & 216 & 152 & 528 \\ 1878 & 157 & 203 & 147 & 507\end{array}$


Do tyske Rigwagswalle i Norlshovig.

\begin{tabular}{|c|c|c|c|c|}
\hline $\begin{array}{l}\operatorname{tar} \\
1 \times x_{1}\end{array}$ & $\begin{array}{l}\text { N. F. } \\
167\end{array}$ & $\begin{array}{l}\text { A. F. } \\
2 ; 3.5\end{array}$ & $\begin{array}{l}\text { J. V. } \\
\text { l(it) }\end{array}$ & $\begin{array}{c}\text { tilsammen } \\
562\end{array}$ \\
\hline $18 \times 4$ & 2.25 & 245 & 1()() & (i6i) \\
\hline $18 \times 6$ & 256 & 275 & 173 & 7014 \\
\hline $1 \times 67$ & $29)$ & $3 \cdot 3$ & $\underline{-2} \cdot \underline{1}$ & 848 \\
\hline $18 ! 10$ & $2 \times 8$ & $3: 0 ;$ & $2 \cdot 2 \cdot 3$ & 837 \\
\hline 1893 & 293 & 311 & 2.233 & 827 \\
\hline 1898 & 350 & 356 & 2.53 & 959 \\
\hline 19012 & 473 & 39.5 & 3011 & 1169 \\
\hline 19113 & ' $1 \times 1$ & 44:1 & 307 & 1是保 \\
\hline 19() & $\pi$ & $4 \cdot 2 \cdot 4$ & 351 & 13333 \\
\hline $19(07$ & 577 & $4(1) .5$ & $3.51 ;$ & 1338 \\
\hline 1912 & 239 & $4 \cdot 2 \cdot 2$ & 3.51 & 1012 \\
\hline
\end{tabular}

2. Haderslev lesteram $t$.

Roddingegnen betegnes med R. F., Toftlundegnen med T. E. og Hvideding Herred mend II. H.

\begin{tabular}{|c|c|c|c|c|}
\hline Aar & K. L. & T. $\mathrm{i}$. & 11. 11. & tilsammen \\
\hline 1871 & 108 & 28 & 40 & 185 \\
\hline 187' & $13: 2$ & 9.5 & 77 & 304 \\
\hline 1877 & 1:)4 & $91: 3$ & 71 & 318 \\
\hline 1878 & 133 & 99 & (i) & $2 y=3$ \\
\hline 1881 & 128 & 107 & 7.5 & 310 \\
\hline 1Sk' & 16.5 & $12 k$ & 102 & 395 \\
\hline $1886 t$ & 162 & $14 . \overline{7}$ & 14t & 4.53 \\
\hline 1887 & 218 & $1(i 2)$ & 200 & 580 \\
\hline 1890 & 194 & 129 & 196 & 519 \\
\hline $189 ; 3$ & $\underline{2}()()$ & $1: 37$ & 213 & 540 \\
\hline 1898 & $3 / 4$ & 1.51 & 2611 & 759 \\
\hline 1902 & $4(0) .5$ & $2(17$ & 3.46 & 958 \\
\hline 1903 & 436 & $2-2 \cdot 4$ & 336 & 996 \\
\hline 19$)(6$ & $4(1) 3$ & 249 & 346 & 10.58 \\
\hline 1907 & 450 & 258 & 351 & 1059 \\
\hline 1912 & 482 & 261 & $35 \overline{\mathrm{i}}$ & 1098 \\
\hline
\end{tabular}

3. Sonderborg A m t.

Als Nørreherred betegnes med A. N., Als Sunderherred med A. S. og Sundered med Sr. 


\begin{tabular}{|c|c|c|c|c|}
\hline Aar & A. $\mathrm{S}$. & A. $\mathrm{s}$ & Siv. & tilsammen \\
\hline 1871 & 78 & 81 & 107 & 266 \\
\hline 1874 & 55 & 50 & 114 & 219 \\
\hline 1877 & 125 & 159 & 218 & 502 \\
\hline 1878 & 15 & 178 & 291 & 627 \\
\hline 1881 & 133 & 158 & 211 & 502 \\
\hline 1884 & 147 & 14.5 & 260 & 552 \\
\hline 1886 & 165 & 171 & 217 & 5.53 \\
\hline 1887 & 214 & 214 & 268 & 696 \\
\hline 1890 & 188 & 195 & 235 & 618 \\
\hline 1893 & 141 & $2 \cdot 33$ & 231 & 595 \\
\hline 1898 & 195 & 247 & 287 & 729 \\
\hline $19(12$ & 210 & 3330 & 355 & 895 \\
\hline $19(1) 3$ & $2(i)$ & 366 & 507 & 1133 \\
\hline 19$)(1) 6$ & 277 & 378 & 498 & 1153 \\
\hline $1 !) 7$ & 2677 & 373 & 518 & 1158 \\
\hline 1912 & 214 & 334 & 480 & 1028 \\
\hline
\end{tabular}
4. A a benra a A t.

Den nordvestlige Del betegnes med $\mathrm{N}$. V. og den sydastlige Tel med S. ().

\begin{tabular}{|c|c|c|c|}
\hline Aar & N. $V$. & S. 1. & tilsammint \\
\hline 1871 & 298 & 362 & 660 \\
\hline 1874 & 307 & 347 & 654 \\
\hline 1877 & 313 & 410 & 753 \\
\hline 187x & 317 & 357 & 6774 \\
\hline 1881 & $29: 3$ & 324 & 617 \\
\hline $1 \times \times 1$ & 338 & 368 & 701 \\
\hline 1886 & 35.3 & 383 & 736 \\
\hline 1887 & 4.41 & 458 & 899 \\
\hline $18 ! \%$ & 515 & 486 & 1001 \\
\hline 1893 & 540 & 510 & 10.50 \\
\hline $18 ! x$ & 586 & 544 & 1130 \\
\hline 19013 & $\bar{\partial})(j$ & 552 & 1148 \\
\hline 1907 & $717^{\circ}$ & 750 & 1467 \\
\hline 1912 & 739.9 & 711 & $14: 50$ \\
\hline
\end{tabular}


De tyske Rigsdatesvaly i Nordslesvig.

\section{'Tabel V.}

De tyske Strmmetal i de enkelte Lamddistrikter.

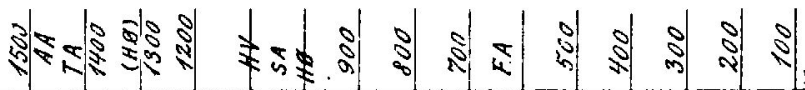

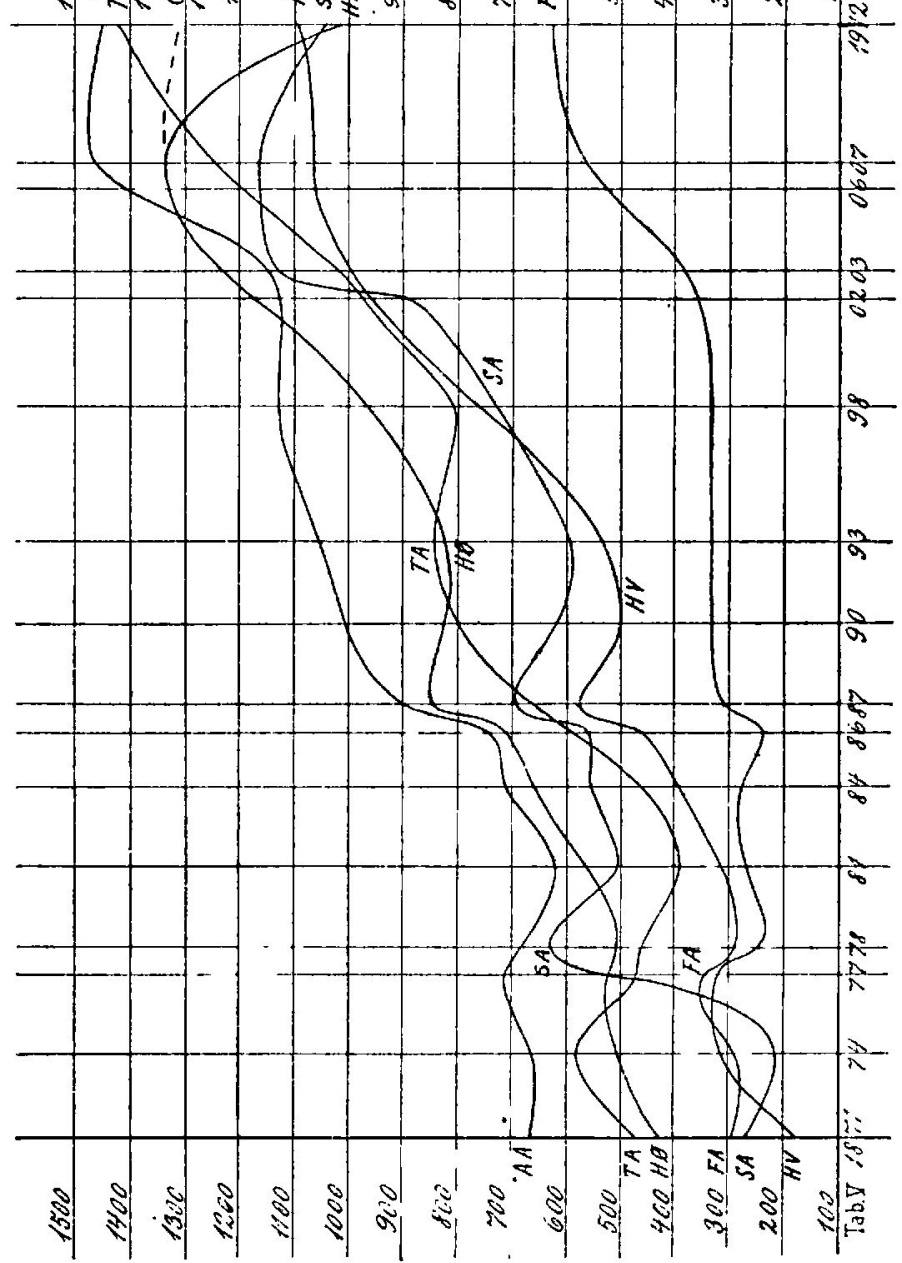

Ho Haderslev (tsteraut, At Aabenra Amt,

HV - Haderslev Vesteramt. $\quad$ H.l $=$ - Flonsborg Amt,

SA: - somblerborg Aut, TA Tumbler Aut. 
5. Fle nborgAmt.

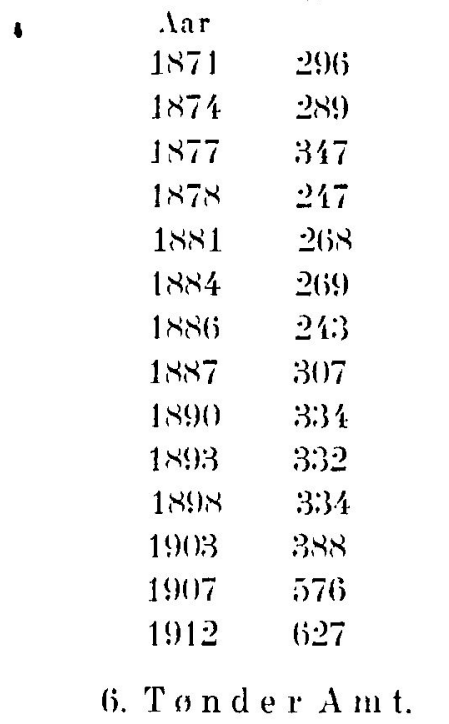

Den ostlige T)el betegnes med T. Ø. og den vestlige Del med T. $\mathrm{r}$.

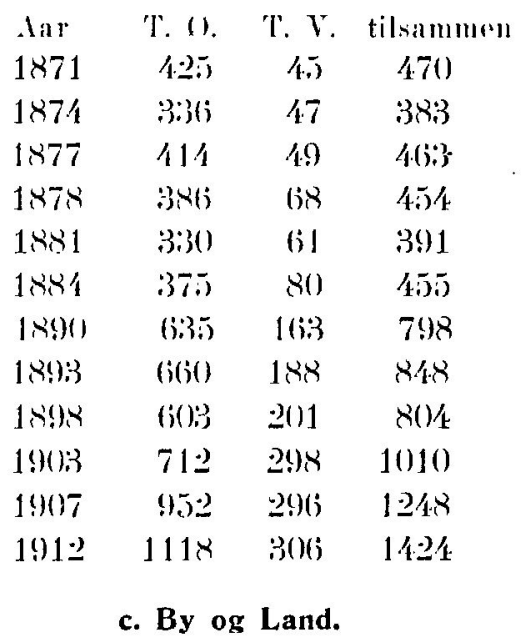

1. I) e enkelte Amter.

a) Fortse Valgkreds (By- ogr Landdistrikter tilsam- 
men ): Haderslevdsteramt betegnes med H. Ø., Haderslev Vesteramt med H. V. og Sonderborg Amt med S. A.

\begin{tabular}{|c|c|c|c|c|}
\hline $\begin{array}{l}A a r \\
871\end{array}$ & 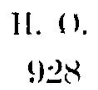 & $\begin{array}{r}\text { H. V. } \\
18.5\end{array}$ & $\begin{array}{l}\text { S. A. } \\
5020\end{array}$ & $\begin{array}{c}\text { tilsamm } \\
1675\end{array}$ \\
\hline 1874 & 1159 & 3014 & 513 & 1976 \\
\hline 1877 & איגינ:1 & 318 & 319 & 2477 \\
\hline ה78 & 1196 & 292 & 1066 & 2554 \\
\hline$x \times 1$ & 1274 & 310 & 934 & 2518 \\
\hline 14 & $13 \times 2$ & 395 & $99 / 4$ & 2771 \\
\hline 18866 & $14 \overline{7}(9)$ & 453 & 10.5 & 2957 \\
\hline 887 & 1684 & 580 & 12.28 & 3492 \\
\hline 890 & 1621 & 519 & 1070 & 3210 \\
\hline $3 ! 3: 3$ & 15.57 & $5 / 40$ & 1032 & 3129 \\
\hline גואוה & 1696 & 759 & 1254 & 3709 \\
\hline$(4) \cdot 2$ & $20: 37$ & 9.58 & 1534 & 4529 \\
\hline 19013 & 2016 & 996 & 1798 & 4862 \\
\hline 19()$(i$ & 213.5 & אי5. & $19-20$ & 5113 \\
\hline 1907 & 2213 & 105!! & $18(1) 4$ & 5166 \\
\hline (1) 1 & $2 \cdot 0(5.5$ & 1098 & 190 & 5211 \\
\hline
\end{tabular}

b) Jen nordslesvigske Iel af anden og fjerde Valgkreds (By-ogr Landdistrikter tilsammen, dog Byerne Flensborg, Tonder og Hojer ikke medregnede). Aahenraa Aint betegnes med A. A., Flensborg Amt med F. A. og Tonder Amt T. A.

$\begin{array}{lrrr}\text { Aar } & \text { A. A. } & \text { F. 1. } & \text { T. A. } \\ 1871 & 1068 & 2966 & 539 \\ 1874 & 1073 & 289 & 440 \\ 1877 & 1210 & 3347 & 539 \\ 1878 & 1101 & 247 & 519 \\ 1881 & 947 & 268 & 461 \\ 1884 & 11299 & 269 & 554 \\ 1886 & 1168 & 243 & 684 \\ 1887 & 1397 & 307 & 749 \\ 1890 & 1563 & 384 & 947\end{array}$




$\begin{array}{lccr}\text { Aar } & \text { A. A. } & \text { F. A. } & \text { T. A. } \\ 1893 & 1598 & 332 & 967 \\ 1898 & 1759 & 334 & 942 \\ 1903 & 1751 & 388 & 1133 \\ 1907 & 2122 & 576 & 1403 \\ 1912 & 2232 & 627 & 1593\end{array}$

2. Hele Nordslesvig.

Til Slutning sammenfattes de tyske Stemmetal

a) i de nordslesvigske Byer, d. v. s. Kobstaderne Hadersler, Sonderborg og Aabenraa og Flækkerne Kristiansfelt, Nordborg, Augustenborg og Logumkloster,

b) i alle nordslesvigske Landdistrikter, og

c) i begge Dele tilsammen, altsaa i hele Nordslesvig. Aar Byerne Landeli- Hele Nordstrikterue slesvig

$\begin{array}{llll}1871 & 1278 & 2300) & 3578 \\ 1874 & 1421 & 2357 & 3778 \\ 1877 & 1662 & 2911 & 4573 \\ 1878 & 1620 & 2801 & 4121 \\ 1881 & 1544 & 2650 & 4194 \\ 1884 & 1686 & 3037 & 4723 \\ 1886 & 1789 & 3263 & 5052 \\ 1887 & 1986 & 3959 & 5945 \\ 1890 & 1947 & 4107 & 6054 \\ 1893 & 1834 & 4192 & 6026 \\ 1898 & 2029 & 4715 & 6744 \\ 1903 & 2219 & 5792 & 8011 \\ 1907 & 2421 & 6691 & 9112 \\ 1912 & 3024 & 6643 & 9667\end{array}$

I Modsæetning til den danske Hefolkning har Tyskerne i Nordslesvig hrerken lidt sarlige Tab ved Udvandringer eller været udsätte for Tryk bort fra Valg- 
1. luen, men de har trart imod jæunlig faret rigelig 'Tilvakst red Indvandring sydfra, ikke blot af Arbejdere ug Nyijggere, nien navnlig af Emberls- og Bestillingsmanl, og de er baade af Myndigheder og prirate Fortyskningsmænd stadig blevne stærkt animerede til i sluttet Filok at afgive deres Stemmesedler.

Som Folge deraf er Beragelsen i de tyske Stemmetal $i$ alt vasentligl opadgaaende; men da hverken hine Indrandringer i deres Omfang eller disse Tilskyndelser $i$ deres Virkninger kan raere absolut regelmassige, er det ganske naturligt, at der undertiden indtræeder mindre Svingninger, saaledes for hele Nordslesvigs saavel som for de samlede Byers og Landdistrikters Vedkommende ved Nedgangen i Aaret 1881, i Haderslev, Nordborg og Løgunkloster samt Sonderborg Amts Landdistrikt ved Nedgangen i 1893 o. s. v. En parafaldende stark Stigning foregaar fra 1886 til 1887, altsaa i det samme Aar, da Stromkantringen i de danske Stemmelals Bevagelse indtræiler. (Jf. Tab. IV og V.)

\section{I. De socialistiske Stemmer.}

a. Byerne.

1. Kabstader ne.

Aar Haders- Sim- Aahen- Flenslev derbore raa bore

$\begin{array}{rrrrr}1874 & - & - & 50 & 659 \\ 1877 & 3 & 33 & 25 & 585 \\ 1890 & 23 & 38 & 49 & 2543 \\ 1893 & 38 & 20 & 80 & 2841 \\ 1898 & 111 & 43 & 98 & 2934 \\ 1903 & 146 & 105 & 193 & 3396 \\ 1907 & 152 & 200 & 271 & 4871 \\ 1912 & 335 & 302 & 305 & 5691\end{array}$


Pata det Onyradade, der nu svarer til Haderslev Tobstad, valgtes der i 1907 tilsammen 293 socialister.

2. Flakkerne.

Aar Ĺristi- Nord- Au- Logumansfelt borg gusten-kloster horg

$\begin{array}{lrrrr}1874 & - & - & - & - \\ 1877 & - & - & 1 & - \\ 1890 & - & - & - & - \\ 1893 & 1 & 2 & - & 6 \\ 1898 & 1 & 2 & 3 & 17 \\ 190 \% 3 & - & 5 & - & 27 \\ 19(17 & - & 4 & - & 16 \\ 191.2 & 2 & 7 & 9 & 18\end{array}$

b. Landit

1. Forste Valgkreds.

Inaderslev (sitermunt betegnes med H. Ø., Hadersler Vesteramt med H. V. og Sonderborg Amt med s.'. A.

Aar H. (1. H. V. S. A. tilsammen

$\begin{array}{rrrrr}1874 & - & - & - & - \\ 1877 & 3 & - & 5 & 8 \\ 1890 & 7 & - & 79 & 86 \\ 18933 & 15 & 3 & 114 & 132 \\ 1896 & 692 & 41 & 82 & 184 \\ 19913 & 135 & 50 & 270 & 455 \\ 1907 & 136 & 44 & 242 & 422 \\ 1912 & 79 & 41 & 334 & 454\end{array}$

2 Andenogfjerde Valgkreds.

Aabenrata Amt betegnes med A. A., Flensborg Ant med F. A. ong Tunder Ant med T. A.

$\begin{array}{lrrcc}\text { Aar } & \text { A. A. } & \text { F. A. } & \text { T. A. } & \text { tilsammen } \\ 1874 & 18 & 10 & - & 28 \\ 1877 & 14 & 32 & 21 & 67\end{array}$


Do tyoke Rignlagsvalg i Sorlslesvie.

\section{T'abel VI.}

1)e sorialistiska sitermmer.

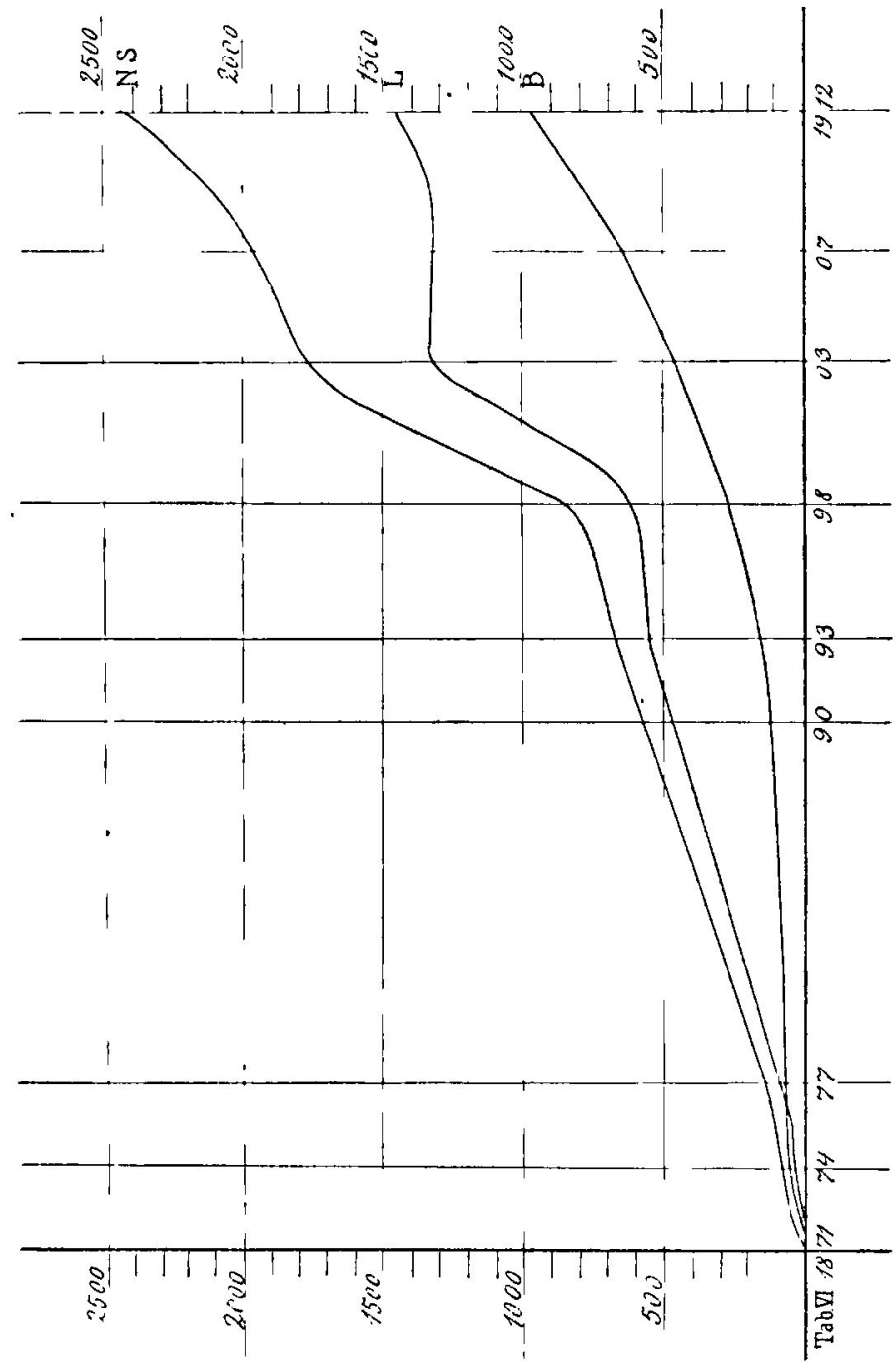

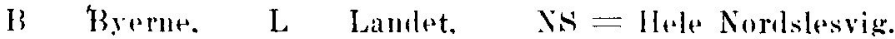




\begin{tabular}{lcccc} 
Aar & A. A. & \multicolumn{2}{c}{ F. A. T. A. tilsammen } \\
1890 & 185 & 208 & - & 393 \\
1893 & 172 & 210 & 12 & 394 \\
1898 & 155 & 236 & 29 & 420 \\
1903 & 380 & 388 & 86 & 854 \\
1907 & 281 & 576 & 39 & 896 \\
1912 & 409 & 508 & 88 & 1005
\end{tabular}

\section{c. By og Land.}

1. De enkelte A inter.

Haderslev Amt betegnes med H. A., Sonderborg Amt med S. A., Aabenraa Amt med A. A. og Tonder Aint med T. A.

$\begin{array}{lrrrr}\text { Aar } & \text { H. A. } & \text { N. A. } & \text { A. A. } & \text { T. A. } \\ 1874 & - & - & 68 & - \\ 1877 & 6 & 39 & 39 & 21 \\ 1890 & 30 & 117 & 234 & - \\ 1893 & 57 & 136 & 252 & 18 \\ 1898 & 214 & 130 & 253 & 46 \\ 1903 & 331 & 3800 & 573 & 113 \\ 1907 & 332 & 446 & 552 & 55 \\ 1912 & 457 & 652 & 714 & 106\end{array}$

2. Hele Nordslesrig.

Byerne betegnes med B., Landdistrikterne med L. og hele Nordslesvig med N. S.

$\begin{array}{rrrr}\text { Aar } & \text { B. } & \text { L. } & \text { N. S. } \\ 1874 & 50 & 28 & 78 \\ 1877 & 62 & 75 & 137 \\ 1890 & 110 & 479 & 589 \\ 1893 & 147 & 526 & 673 \\ 1898 & 275 & 604 & 879 \\ 1903 & 476 & 1309 & 1785 \\ 1907 & 643 & 1318 & 1961 \\ 1912 & 978 & 1459 & 2437\end{array}$


Det socialistiske Stemmetal stiger altsaa stadig, nestén parabolsk, i Byerne. Paa Landet foregaar der en særlig stærk stigning i Tidsrummet fra 1898 til 19013, men efter den Tid er den opadganende Bevægelse forholdsris ringe (jf. Tab. VI.); der er, som én af Socjaldemokraternes intellegenteste Forere i Hertugdommerne kort for det sidste Rigsdagsvalg havde Lejligher til at ytre, i Nordslesvig ikke noget egentligt Proletariat og derfor heller ikke nogen rigtig Jordbund for Socialdemokratiet.

\section{B. Relative Tal.}

\section{De danske og tyske Stemmer.}

De efterfolgende Tabeller vil vise, hror mange danske og tyske Stemmer der i enkelte Distrikter og indenfor samlede (Omrader er blevet afgivet af hver 100 afgiwne danske og tyske Stemmer tilsammen. Derred betegnes dinnk, med d., tysk med t.

\section{a. Byerne.}

1. Købstæderne.

\begin{tabular}{|c|c|c|c|c|c|c|}
\hline \multirow[t]{2}{*}{ Lar } & \multicolumn{2}{|c|}{ Hablerslev } & \multicolumn{2}{|c|}{ Sunderborg } & \multicolumn{2}{|c|}{ Aabenraa } \\
\hline & & t. & d. & t. & & \\
\hline 871 & 58.5 & 41.5 & 56.0 & 4.4. 1$)$ & 47.6 & 52.4 \\
\hline $27 x$ & 50.9 & $4 !)$ & 2 & 代 & b) & 3.3. \\
\hline 877 & 44.2 & 5.5 & 1 & 47 & .5 & 59 \\
\hline 878 & 4.2 .5 & 57. & 2 & 50 & 2.8 & 57 \\
\hline א & 36.5 & (i3.). & 2 & 50 & .6 & 59 \\
\hline 384 & 34.1 & (6i). 9 & (i) & 51 & 3.6 & i4.4 \\
\hline 8 & 30.0 & $7(1)$ & .1 & os & 34.2 & 65.8 \\
\hline & 32.6 & 67. & 1 & 60 & 33.4 & $(36.6$ \\
\hline & 35.9 & 64.1 1 & .3 & 54 & (1). & (i) \\
\hline גט & 38.9 & (i1.1 & 51.6 & $4 \times .4$ & 34.8 & 65.2 \\
\hline
\end{tabular}




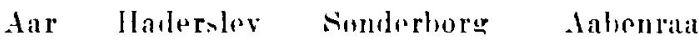
d. t. d. t. d. t.

$1898 \quad 42.0 \quad 5 \times 10 \quad 43.0 \quad 57.0 \quad 33.6 \quad(60.4$ 19(1.) $336.3 \quad 63.7 \quad 31.3 \quad$ (38.7 $\quad$ -

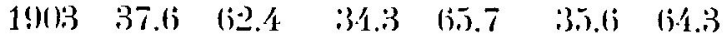
$1906 \quad 39.4$ (60.6 25.5 74.5 - $1907 \quad 37.4 \quad 6.2 .2 \quad 30.4 \quad 69.2 \quad 33.7 \quad 66.3$ 1912 $\quad 4(1.5) \quad 59.5 \quad 31.4 \quad(39.2 \quad 3.2 .4 \quad 67.6$

․ Flakker n

a Forste Valgk reds:

Aar Kristiausfelt Nordlourg Ausustenborg d. t. $\quad$ l. t. $\quad$ l. $t$.

$\begin{array}{lllllll}1871 & 5(6.2 & 43.8 & 81.5 & 18.5 & 15.3 & 84.7\end{array}$

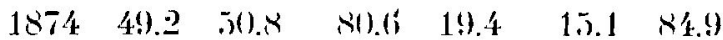
$\begin{array}{lllllll}1877 & 45.7 & 51.3 & (51.2 & 38.8 & 5.4 & 9.4 .(3\end{array}$ $\begin{array}{lllllll}1878 & 42.1 & 57.9 & (33.4 & 30.6 & \$ .7 & \$ 1.3\end{array}$

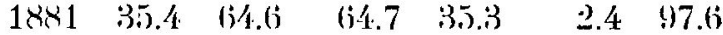
$\begin{array}{lllllll}1 \times 84 & 34.9 & 6.5 .1 & 50.4 & 49.6 & 1.2 & \text { แ下.8 }\end{array}$ $\begin{array}{lllllll}18 \times(j & 30.3 & 69.7 & 43.4 & 56.6 & 2.3 & 97.7\end{array}$ $\begin{array}{lllllll}1887 & 30.3 & \mathbf{6 9} 9.7 & 46.0 & 54.0 & 3.8 & 96.2\end{array}$

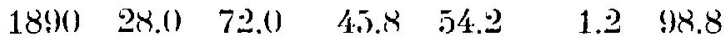
$\begin{array}{lllllll}189.3 & 39.0 & 61.0 & 53.0 & 47.0 & 9.5 & 90.5\end{array}$ $\begin{array}{lllllll}1898 & 36.6 & 63.4 & 44.6 & 55.4 & 12.9 & 87.1\end{array}$ $\begin{array}{lllllll}1902 & 32.1 & 67.9 & 43.7 & 56.3 & 17.6 & 82.4\end{array}$

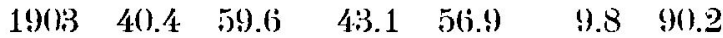
$1906 \quad 43.3 \quad 56.7 \quad 41.0 \quad 59.0 \quad 27.4 \quad 72.6$ $19(17 \quad 46.4 \quad 53.6 \quad 42.9 \quad 57.1 \quad 24.8 \quad 75.2$ $1912 \quad 45.6 \quad 54.2 \quad 45 .(1 \quad 55.0 \quad 24.8 \quad 7.5 .2$

b Anden og fjerde Valgkreds:

Aar (iraasten med Adsbøl Logumkloster d. t. d. t.

$\begin{array}{lllll}1871 & 65.6 & 34.4 & \mathbf{6 1 . 7} & 38.3\end{array}$ $\begin{array}{lllll}1874 & 74.3 & 25.7 & 69.2 & 30.8\end{array}$ $\begin{array}{lllll}1877 & 61.6 & 38.4 & 02.2 & 37.8\end{array}$ $\begin{array}{lllll}1878 & 64.3 & 35.7 & 61.3 & 38.7\end{array}$ 
Aar Graasten med Ansbul Lunumkloster

\begin{tabular}{|c|c|c|c|c|}
\hline & 1. & t. & A. & t. \\
\hline $1 \times 81$ & 57.1 & 42.9 & 51.7 & 4.8 .3 \\
\hline $18 \times 4$ & 57.5 & 42.5 & 39.3 & (bi).7 \\
\hline $18 \times 6$ & (i1.9) & 38.1 & - & - \\
\hline $18 \times 7$ & $5(6.0$ & 44.0 & - & - \\
\hline 1860 & $5(j .5)$ & 43.5 & $3 \cdot 2.3$ & (i7.7 \\
\hline 1893 & 56.3 & 43.7 & 35.3 & 64.7 \\
\hline 1898 & 51.5 & 48.5 & 28.1 & 71. \\
\hline $19(1) 3$ & 53.0 & 47.0 & 33.5 & $(j 6.5$ \\
\hline 1907 & 51.1 & 48.9 & 33.5 & 60 \\
\hline 1912 & 51.5 & 48.5 & 33.5 & (iti.; \\
\hline
\end{tabular}

\section{b. Landet.}

1. Forste Valgkreds.

Haderslev Østeramt betegnes med H. (1., Hader'slev Vesteramt med H. V., og Simderborg Ant merl S. A.

Aar
II. (1).

1. t.
11. $v$.

d. t. s. 1.

ll. t.

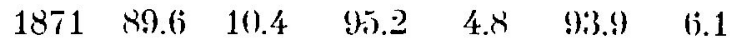
$\begin{array}{lllllll}1874 & 86.5 & 13.5 & 91.6 & 8.4 & 95.1 & 4.9\end{array}$ $\begin{array}{lllllll}1877 & 84.9 & 15.1 & 9(1.3 & 9.7 & \times .4 .4 & 11.6\end{array}$ $\begin{array}{lllllll}1878 & 84.6 & 15.4 & 90.6 & 9.4 & \$ 4.7 & 15.3\end{array}$ $\begin{array}{lllllll}1881 & 81.6 & 18.4 & 89.3 & 10.7 & 86.6 & 13.4\end{array}$ $\begin{array}{lllllll}1884 & 78.1 & 21.9 & 8.5 .3 & 14.7 & 84.5 & 15.5\end{array}$ $\begin{array}{lllllll}1886 & 76.2 & 23.8 & 83 .(1) & 17.0 & 8.3 .2 & 16.8\end{array}$ $\begin{array}{lllllll}1887 & 73.6 & 26.4 & 8(1.5) & 19.5 & 81.4 & 18.6\end{array}$ $1890 \quad 74.4 \quad 25.6 \quad 82.4 \quad 17.6 \quad 83.4 \quad 16.6$

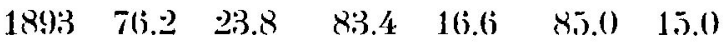
$\begin{array}{lllllll}1898 & 74.3 & 25.7 & 79.4 & 20.6 & 84.1 & 15.9\end{array}$

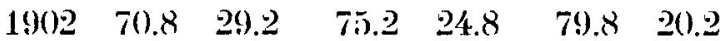

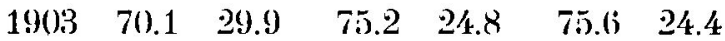

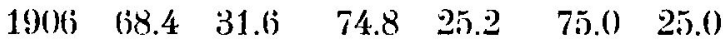
$\begin{array}{lllllll}1907 & \mathbf{6 8 . 8} & 31.2 & 74.6 & 25.4 & 74.9 & 25.1\end{array}$ $\begin{array}{lllllll}1912 & 75.7 & 24.3 & 76.3 & 23.7 & 78.7 & 21.3\end{array}$ 
2. A n d e n o g f jerde V a lgkreds. Aabenraa Amt betegnes med A. A., Flensborg Amt med F. A., og Tonder Norreamt med T. A.

\begin{tabular}{|c|c|c|c|c|c|c|}
\hline \multirow[t]{2}{*}{ Aar } & \multicolumn{2}{|c|}{ A. A. } & \multicolumn{2}{|c|}{ F. A. } & \multicolumn{2}{|c|}{ T. A. } \\
\hline & d. & t. & il. & t. & d. & t. \\
\hline 1871 & 79.0 & 21.0 & 66.0 & 34.0 & 84.6 & 15.4 \\
\hline 1874 & 79.0 & 21.0 & (iti.0 & 34.0 & 86.6 & 13.4 \\
\hline 1877 & 74.1 & 25.9 & 56.7 & 43.3 & 80.5 & 19.5 \\
\hline 1878 & 73.3 & 20.7 & $(i 2.0)$ & 38.0 & 79.8 & 20.2 \\
\hline $1 \times \times 1$ & 72.2 & 27.8 & 56.7 & 43.3 & 79.0 & 21.0 \\
\hline $1 \times 84$ & 72.9 & $27: 1$ & (62.9) & 37.1 & 72.5 & 27.5 \\
\hline $1 \times 86$ & 72.4 & 27.6 & 63.3 & 36.7 & - & - \\
\hline 1887 & 69.1 & 30.9 & 57.1 & 42.9 & - & - \\
\hline 1890 & 65.0 & 35.0 & 52.1 & 47.9 & 66.8 & 33.2 \\
\hline $1 \times 93$ & 65.2 & 34.8 & 46.3 & 53.7 & 63.6 & 36.4 \\
\hline 1898 & 64.6 & 35.4 & 52.4 & 47.6 & 66.1 & 33.9 \\
\hline 19() 3 & $(i 2.0)$ & 38.0 & 40.8 & 59.2 & 59.3 & 40.7 \\
\hline $19(1) 7$ & 58.6 & 41.4 & 36.1 & 63.9 & 56.3 & 4.3 .7 \\
\hline 1912 & (i.2.3 & 37.7 & 31.0 & 69.0 & 55.3 & 44.7 \\
\hline
\end{tabular}

1. Ue enkelte Amter.

a. Forste Valgkreds: Haderslev og Sonderhorg Anter.

\begin{tabular}{|c|c|c|c|c|}
\hline \multirow[t]{2}{*}{ Aar } & \multicolumn{2}{|c|}{ II. A. } & \multicolumn{2}{|c|}{ S. A. } \\
\hline & d. & t. & d. & t. \\
\hline 1871 & 87.8 & 12.2 & 89.0 & 11.0 \\
\hline 1874 & 83.2 & 16.8 & 90.1 & 9.9 \\
\hline 1877 & 80.8 & 19.2 & 81.9 & 18.1 \\
\hline & $8(1) .4$ & 19.6 & 78.4 & 21.6 \\
\hline 1881 & 77.6 & 22.4 & 79.5 & $2(0.5)$ \\
\hline $1 \times 84$ & 73.9 & 26.1 & 77.1 & 22.9 \\
\hline 1886 & 71.3 & 28.7 & 74.9 & 2.5 .1 \\
\hline $1 \times 87$ & (6!).5) & 30.5 & 73.2 & $2(i .8$ \\
\hline 18.40 & 71.2 & 28.8 & 76.1 & 23.9 \\
\hline $1 \times 9) 3$ & 73.5 & $2(i, 5)$ & 78.6 & 21.4 \\
\hline
\end{tabular}


De tyske Rigsdagsvalg i Nordslesvig.

\begin{tabular}{ccccc} 
Aar & \multicolumn{2}{c}{ H. A. } & \multicolumn{2}{c}{ S. A. } \\
& d. & t. & d. & t. \\
1898 & 71.7 & 28.3 & 77.1 & 22.9 \\
1902 & 67.5 & 32.5 & 71.4 & 28.6 \\
1903 & 67.7 & 32.3 & 68.1 & 31.9 \\
1906 & 67.2 & 32.8 & 65.6 & 34.4 \\
1907 & 66.9 & 33.1 & 66.8 & 33.2 \\
1912 & 69.5 & 30.5 & 69.0 & 31.0
\end{tabular}

b. Af anden og fjerde Valgkreds: Aabenraa og Tønder Amter.

\begin{tabular}{ccccc} 
Aar & \multicolumn{2}{c}{ A. } & & \multicolumn{2}{c}{ T. A. } \\
& d. & t. & d. & t. \\
1871 & 72.8 & 27.2 & 83.3 & 16.7 \\
1874 & 72.4 & 27.6 & 85.5 & 14.5 \\
1877 & 67.1 & 32.9 & 79.0 & 21.0 \\
1878 & 66.3 & 33.7 & 78.5 & 21.5 \\
1881 & 65.9 & 34.1 & 77.0 & 23.0 \\
1884 & 65.4 & 34.6 & 69.5 & 30.5 \\
1886 & 64.9 & 35.1 & 64.2 & 35.8 \\
1887 & 61.8 & 38.2 & 63.5 & 36.5 \\
1890 & 57.4 & 42.6 & 64.0 & 36.0 \\
1893 & 58.5 & 41.5 & 61.5 & 38.5 \\
1898 & 57.5 & 42.5 & 63.3 & 36.7 \\
$19(1)$ & 55.8 & 44.2 & 57.5 & 42.5 \\
$19(07$ & 53.2 & 46.8 & 54.6 & 45.4 \\
1912 & 55.4 & 44.6 & 53.7 & 46.3
\end{tabular}

2. Hele $\mathrm{Nordslesvig.}$

Byerne betegnes med B., Landdistrikterne med L. og hele Nordslesvig med N. S.

Aar

d. B.

t.

$\begin{array}{lll}1871 & 55.8 & 44.2\end{array}$

$\begin{array}{lll}1874 & 53.3 & 4.6 .7\end{array}$

$\begin{array}{lll}1877 & 45.7 & 54.3\end{array}$

$1878 \quad 45.0 \quad 55.0$
L.

d. t.

$88.1 \quad 11.9$

$87.3 \quad 12.7 \quad 82.6 \quad 17.4$

$\begin{array}{llll}83.0 & 17.0 & 77.3 & 22.7\end{array}$

$82.4 \quad 17.6 \quad 76.6 \quad 23.4$
N. S.

d. $t$. 


\begin{tabular}{ccccccc} 
Aar & \multicolumn{2}{c}{ B. } & \multicolumn{2}{c}{ L. } & \multicolumn{2}{c}{ N. s. } \\
& d. & t. & d. & t. & d. & t. \\
1881 & 41.4 & 58.6 & 81.6 & 18.4 & 75.4 & 24.6 \\
1884 & 37.6 & 62.4 & 78.7 & 21.3 & 72.1 & 27.9 \\
1886 & 33.4 & 66.6 & 76.7 & 23.3 & 69.7 & 30.3 \\
1887 & 34.0 & 66.0 & 79.5 & 20.5 & 67.7 & 32.3 \\
1890 & 35.4 & 64.6 & 74.2 & 25.8 & 68.0 & 32.0 \\
1893 & 40.1 & 59.9 & 74.8 & 25.2 & 69.4 & 30.6 \\
1898 & 38.2 & 61.8 & 73.9 & 26.1 & 68.7 & 31.3 \\
1903 & 35.7 & 64.3 & 69.2 & 30.8 & 64.0 & 36.0 \\
1907 & 35.1 & 64.9 & 66.8 & 33.2 & 61.8 & 38.2 \\
1912 & 36.1 & 63.9 & 69.1 & 30.9 & 63.1 & 36.9
\end{tabular}

Det ses altsaa, at det danske Stemmetal ved det sidste Rigsdagsvalg baade $\mathrm{i}$ det hele og par de fleste Steder ikke blot i sig selv, men ogsaa procentualiter $\mathbf{i}$ Forhold til de samlede afgivne danske og tyske Stemmer har været i glædelig Fremgang.

\section{De danske, tyske og socialistiske Stemmer.}

Til Slutning hidsættes endnu nogle Tal; som viser, hvor mange danske, tyske og socialistiske Stemmer der i de nordslesvigske Kobstæeder tilsammen, i Landdistrikterne tilsammen og i hele Nordslesvig er blevet afgivet af hver 100 afgivne Stemmer. Her er dog kun den væsentligste Del af Rigsdagsvalgene medtagne. Over Talrakkerne betegnes dansk med d., tysk med t., og socialistisk med s.

\begin{tabular}{ccccccc} 
Aar & \multicolumn{3}{c}{ Byerne } & \multicolumn{4}{c}{ Landet } \\
& d. & t. & s. & d. & t. & s. \\
1874 & 52.5 & 45.9 & 1.6 & 87.2 & 12.6 & 0.2 \\
1877 & 44.8 & 53.2 & 2.0 & 82.6 & 17.0 & 0.4 \\
1890 & 34.1 & 62.4 & 3.5 & 72.1 & 25.1 & 2.8 \\
1893 & 38.2 & 57.2 & 4.6 & 72.5 & 24.4 & 3.1 \\
1898 & 35.3 & 57.0 & 7.7 & 71.8 & 25.0 & 3.2
\end{tabular}


De tyske Rigsdaysvalg i Nordslesvig.

\begin{tabular}{|c|c|c|c|c|}
\hline \multirow[t]{2}{*}{ Aar } & \multicolumn{3}{|c|}{ Byerne } & \multirow[b]{2}{*}{$\mathrm{d}$. } \\
\hline & d. & t. & s. & \\
\hline 1903 & 31.4 & 56.5 & 12.1 & 64.7 \\
\hline 1907 & 30.0 & 55.3 & 14.7 & 62.7 \\
\hline 1912 & 29.9 & 53.0 & 17.1 & 64.7 \\
\hline & \multicolumn{4}{|c|}{ Hele Nordslesvig: } \\
\hline & Aar & d. & t. & s. \\
\hline & 1874 & 82.3 & 17.4 & 0.3 \\
\hline & 1877 & 76.8 & 22.5 & 0.7 \\
\hline & 1890 & 65.9 & 31.1 & 3.0 \\
\hline & 1893 & 67.1 & 29.6 & 3.3 \\
\hline & 1898 & 66.0 & 30.1 & 3.9 \\
\hline & 1903 & 59.2 & 33.4 & 7.4 \\
\hline & 1907 & 57.1 & 35.3 & 7.6 \\
\hline & 1912 & 57.8 & 33.7 & 8.5 \\
\hline
\end{tabular}

I Forhold til Rigsdagsvalget i 1907 stiller sig altsaa Danskernes, Tyskernes og Socialisternes Vindingsog Tabs-Konto ved sidste Rigsdagsvalg i Procenter af de samlede afgivne Stemmer som folger:

$\begin{array}{lccc} & \begin{array}{c}\text { Byerne } \\ \%\end{array} & \begin{array}{c}\text { Landet } \\ \%\end{array} & \begin{array}{c}\text { Ifele Nordslesvig } \\ \%\end{array} \\ \text { Danskerne } & -0.1 & +2.0 & +0.7 \\ \text { Tyskerne } & -2.3 & -2.3 & -1.6 \\ \text { Socialisterne } & +2.4 & +0.3 & +0.9\end{array}$

